\title{
An analysis of the Syllable Structure of Kikamba Nouns
}

\author{
Dorcas Minoo Kimongo ${ }^{1}$, Dr. Anashia Nancy Ong'onda ${ }^{2}$
}

\author{
${ }^{1}$ School of Social Sciences, Department of Languages and Humanities, Mount Kenya University, Kenya \\ ${ }^{2}$ School of Humanities and Social sciences, Department of Languages and Linguistics, Machakos University, Machakos, Kenya
}

\begin{abstract}
This paper analyses the syllable within the framework of phonology. The syllable is a central prosodic feature in phonology and phonological processes occur within it. However, languages differ with respect to phonotactic constraints that control their syllable structure. Therefore, this paper considers Kikamba language to have unique principles of syllabification that need to be explored. This paper applies the theory of Generative CV-phonology model that was built upon Kahn's (1976) and (Clements \& Keyser, 1983). The study focused on the syllable structure of Kikamba Nouns. The study employed descriptive research design. A sample size of 50 participants was used as respondents in the study. Purposive sampling was used to identify the participants. The data was collected through natural observation and interviews. The data was analyzed qualitatively. The study found that the syllable structure of Kikamba nouns has four syllable structures, that is, $C V, V, C V$ and $C C V$. This study makes significant contribution to theoretical studies of phonetics and phonology by exploring how the phonotactic constraints in Kikamba language lead to organization of words.
\end{abstract}

Keywords - Syllable, syllable structure, Kikamba language.

\section{INTRODUCTION}

A number of scholars define a syllable as a phonological unit of utterance that constitutes an onset, nucleus and coda (Trubetzcoy, 1969; Hyman, 1975; Lass, 1984; Katamba, 1989). Matthews (1997) on the other hand, defines a syllable in close relation to its combination. Matthews, claims that the syllable is, a phonological unit consisting of a vowel or other unit that can be produced in isolation, either alone or accompanied by one or more less sonorous units. Crystal (1997) adds up the aspect of a rhythm in a syllable by noting that a syllable is an element of speech that acts as a unit of rhythm, consisting of a vowel, syllabic, or vowel/consonant combination.

The syllable has a structure. The syllable structure is usually seen as the requirements and constraints which determine the shapes of possible syllables, usually formulated in terms of sequences of consonants and vowels, but also in terms of onset plus rhyme, or onset plus nucleus plus coda (Trask, 1996). The syllable can be divided into two parts: onset and rhyme. Within the rhyme we find the nucleus and coda. Worth noting, is the fact that not all syllables have all parts:

ISSN: 2456-7620

https://dx.doi.org/10.22161/ijels.55.64 the smallest possible syllable contains a nucleus only. That is a syllable may or may not have an onset and a coda.

The Onset is the beginning sounds of the syllable; the ones preceding the nucleus. They are always consonants in English. The nucleus is a vowel in most cases, although the consonants [r], [1], [m], [n] and the velar nasal ( the " ng" sound) can also be the nucleus of a syllable. Yule (1996) notes that, a syllable must contain a vowel ( or vowel like) sound and he points out that the basic elements of the syllable as: Onset (one or more consonants) Rhyme ( consists of the vowel which is treated as the nucleus, plus any following consonant(s),treated as the Coda). The symbol $\sigma$ is used to represent a syllable. The nucleus $(\mathrm{N})$, rhyme is represented as $(\mathrm{R})$, onset is $(\mathrm{O})$. The consonants following the nucleus are grouped together as coda $(\mathrm{Co})$.

The vowel segment usually occupies the nucleus or the central part of the syllable while consonant segments occupy the marginal parts of the syllable, that is, the onset and the coda (Ladefoged, 2000). The nucleus must always be there for a unit to qualify as a syllable. Therefore, a syllable can either be $\mathrm{V}, \mathrm{CV}, \mathrm{VC}$, or $\mathrm{CVC}$. The syllable plays an important role in formation of words in any given language. 
Urua (2000) adds that the syllable provides an anchor on which a number of segmental and suprasegmental phenomena hinge such as pitch and rhythm. Thus, syllables are combined to form words and this triggers phonological processes and all languages have phonotactic constraints that force a particular sequence of words in syllables to occur with acceptable order of languages. This leads to various phonological processes such as vowel harmony, assimilation, deletion, insertion among others. The current study analyzes the syllable structure of Kikamba language. The syllable structure is significant to a language as it is very central in phonological analysis. This is because phonological processes occur within syllables and across syllable boundaries. However, languages differ with respect to phonotactic constraints that control their syllable structure. The phonotactic constraints force the sequence of words in a syllable to agree with a given order of a specific language. It is on the above basis that this paper considers Kikamba language to have unique syllable structure.

\subsection{Kikamba phonological parameters}

According to Greenberg's classification, Kikamba is grouped among the Niger -Congo family as cited in (Whiteley and Muli 1962). Thus, Kikamba is a Bantu language (cf. Guthrie (1948); Heine (2000). According to Maundu (1980)
Kikamba has five varieties, the Kitui North, the central Kitui, Eastern -Southern, Kilungu and Makueni, and Machakos. Kikamba has three major regional dialects, the Machakos dialect is spoken in Machakos County, the Kitui dialect spoken in Kitui and Mwingi counties. The third dialect, Kikilungu, is spoken in a small area of Makueni counties. Kikamba can be classified using phonological, Morphological and syntactic parameters. Phonologically, Kikamba is a seven vowel system language, it prefers the $\mathrm{CV}$ syllable structure, and is tonal. This study seeks to establish the syllable structure of Kikamba nouns.

According to Massamba (1996) every language takes a limited number of sounds from the central pool of human speech sound to form its phonetic inventory. A phonological study of the language examines the structure and the function of the inventory: the sounds that are likely to occur, their possible combinations. Kikamba has a total of 19 consonants (Kitavi, 1992). Mathooko (2004) identifies two more consonants that are found in Kitui North variety. These are the voiced alveolar trill $[\mathrm{r}]$ and the voiced velar fricative [y]. This paper has focused on the Machakos variety or dialect which is recognized as the standard variety and does not have the two additional phonemes. The following is a description of the Kikamba consonants:

Table 1. 1: Kikamba Consonants

\begin{tabular}{|c|c|c|c|c|c|c|}
\hline $\begin{array}{ll}\cdot & \text { Place } \\
\text { Manner }\end{array}$ & Bilabial & Dental & Alveolar & $\begin{array}{l}\text { Palato- } \\
\text { Alveolar }\end{array}$ & palatal & Velar \\
\hline Stops & & & $\mathrm{t}$ & & & $\mathrm{k}$ \\
\hline Prenasalised stops & $\mathrm{mb}$ & & nd & & & yg \\
\hline Affricates & & & & ts & & \\
\hline $\begin{array}{l}\text { Prenasalized } \\
\text { Affricate }\end{array}$ & & & & nd3 & & \\
\hline Fricatives & $\Phi$ & $\theta$ & $\mathrm{S}$ & & & \\
\hline $\begin{array}{l}\text { Prenasalized } \\
\text { Fricatives }\end{array}$ & & ne & $\mathrm{nz}$ & & & \\
\hline Nasals & $\mathrm{m}$ & & $\mathrm{n}$ & & $\mathrm{n}$ & $\eta$ \\
\hline Laterals & & & 1 & & & \\
\hline Glides & w & & & & $\mathrm{j}$ & \\
\hline
\end{tabular}

Kikamba like all the other Central Kenya Bantu languages namely; Kikuyu, Kimeru, Kiembu, Kitharaka and Kimbeere, has seven vowel systems (cf. Kioko 1994). The seven vowels of Kikamba are accompanied by vowel length. Thus, 
Front

Central

Close i

Close - mid $\quad$ e

Open - mid

$\boldsymbol{\varepsilon}$
Back

Open. a

Fig. 1. 1: The vowel Chart

Figure 1.2 below demonstrates

Front

Close

Close - mid

Open-mid

Open ii

ee

$\varepsilon \varepsilon$

$\varepsilon \varepsilon$

วว

Fig.1. 2: Long Vowels 
Table 1.2 below demonstrates the phonetic and orthographical representation of Kikamba vowels

Table 1. 2: Phonetic and Orthographical Representation of Kikamba Vowels

\begin{tabular}{|c|c|c|c|}
\hline $\begin{array}{l}\text { IPA } \\
\text { Symbol }\end{array}$ & $\begin{array}{l}\text { Kikamba } \\
\text { Orthography }\end{array}$ & Examples & Gloss \\
\hline A & $\mathrm{a}$ & vata /vata/ & need \\
\hline$\varepsilon$ & $\mathrm{e}$ & ete / / te/ & bring \\
\hline $\mathrm{E}$ & $\hat{\mathbf{1}}$ & wîa /wea/ & work \\
\hline I & $\mathrm{i}$ & ndia /ndia/ & Fool \\
\hline כ & $\mathrm{O}$ & osa /osa/ & take \\
\hline $\mathrm{O}$ & $\hat{\mathrm{u}}$ & kûna /kona/ & beat \\
\hline $\mathrm{U}$ & $\mathrm{u}$ & mumo /mums/ & Grace \\
\hline
\end{tabular}

The study analyzed the Kikamba syllable structure with a close relation to the parameters discussed above.

\section{GENERATIVE CV-PHONOLOGY MODEL}

Generative CV-phonology model is propounded by Kahn's (1976) and (Clements \& Keyser, 1983). Generative CV Phonology is a non - linear model focused on the syllable structure. Generative CV -Phonology holds that many phonological rules only receive appropriate formulations in terms of the syllable (Roach, 1994). Generative CV has three main tasks. The tasks are: to specify well - formed expressions of the theory, to specify the parameters governing the varying choices of syllable types, and to specify language specific rules that govern syllabification in languages.

Generative CV - Phonology is a non - linear model which has three tiers. Each of the tiers has a certain vocabulary associated with it. The segmental tier has a single column of phonetic features of consonants and vowels. The CV tier has two elements, $\mathrm{C}$ and $\mathrm{V}$ to denote. [- syllabic] and [+syllabic] elements, respectively. The syllable tier is denoted by a single element $(\sigma)$ as demonstrated below:

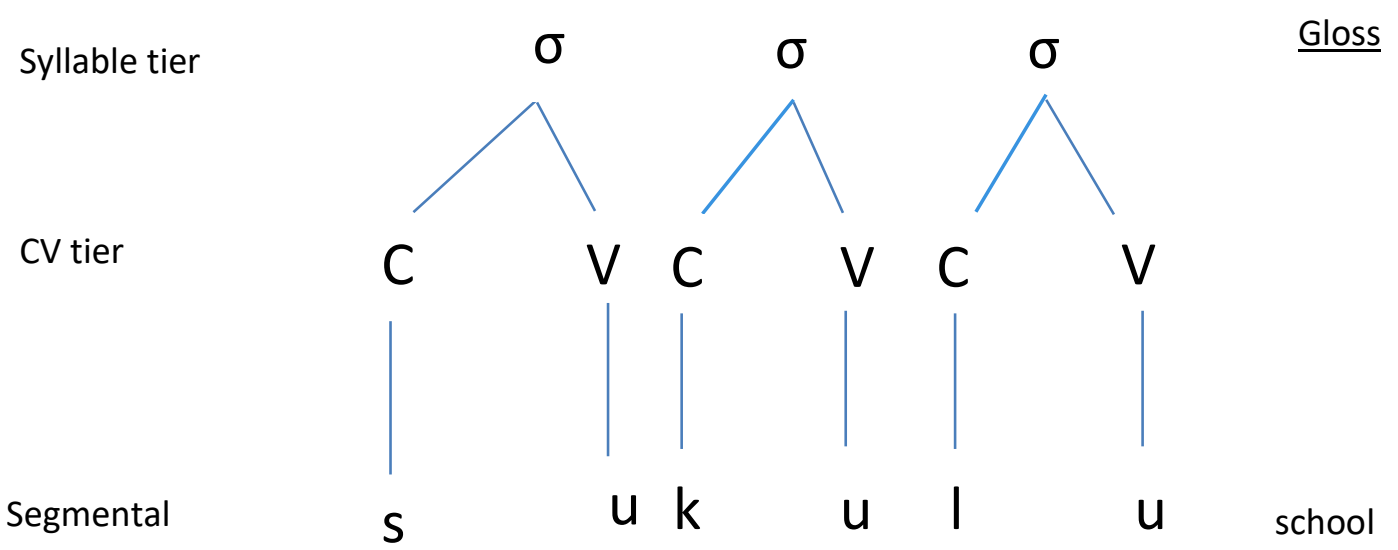

The three tiers are connected to each other using association vowel segments are the immediate constituents of the CV elements. According to Kahn's model of the syllable have two tiers, namely, the syllable tier and segmental tier, as illustrated below. elements. Therefore, the $\mathrm{CV}$ elements are immediate constituents of the syllables. Likewise, the consonant and 
(1)

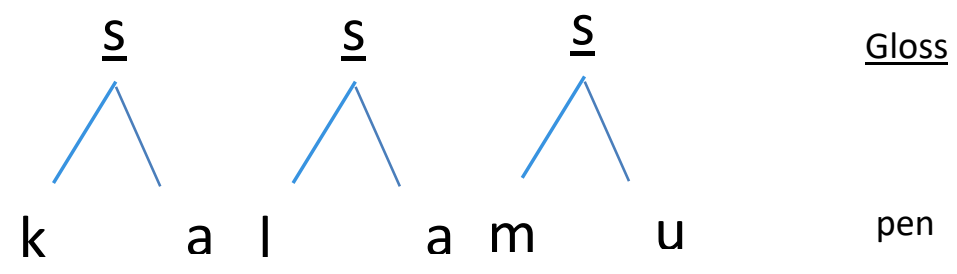

Clements \& Keyser (1983) modified Kahn's model by introducing a third tier, known as CV - tier to mediate between syllable tier and segmental tier. The CV tier was introduced so as to tackle the shortfalls identified in Kahn's model. Thus, the Generative CV-Phonology has three tiers as demonstrated below:

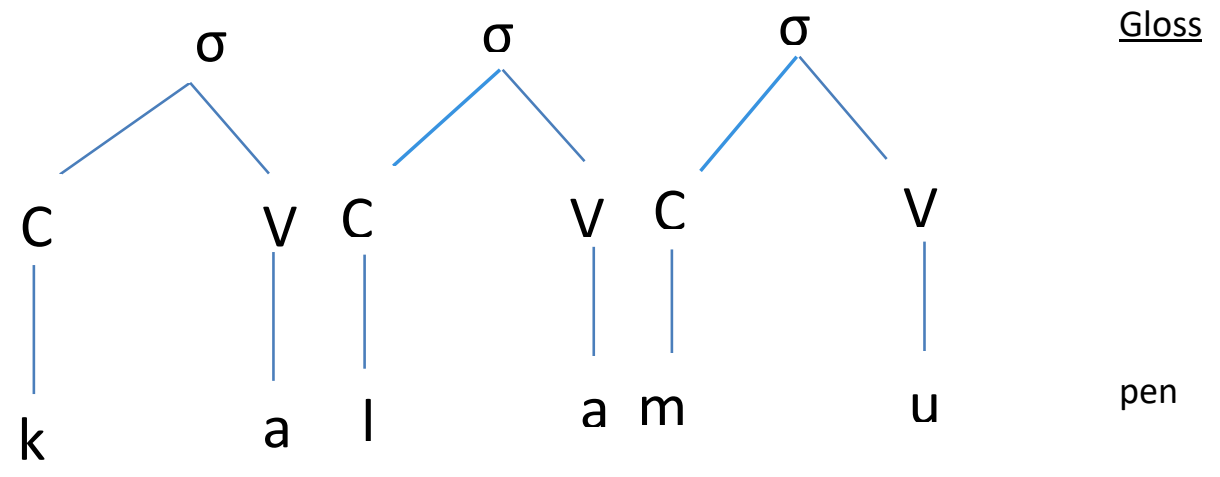

CV-phonology model provides more details about the syllable. Apart from showing the number of syllables that are in a word, CV - Phonology model shows the nucleus and the margins of the syllable. According to Clements \& Keyser (1983), the CV tier distinguishes the functional positions of the elements within a syllable. Elements of each tier distinguish between syllable peaks and syllable margins in that segments dominated by $\mathrm{V}$ elements are the syllable nucleus, while segments dominated by $\mathrm{C}$ elements are the syllable margins. The elements of the $\mathrm{CV}$ tier also serve the function of defining the timing units of speech production in the syllable. Single elements of C or V represent one timing unit; double elements represent two timing units and so on. $\mathrm{CV}$ - tier also plays the role of displaying syllable weight. As discussed in the nucleus, the syllable plays the role of distinguishing between the heavy and light syllables. It is in the CV tier where we see the branching or non- branching of the nucleus, and therefore distinguish the light from the heavy syllable. The aspect of tier is applied in the analysis of the syllable structure of the Kikamba nouns.
The design for the current study was descriptive research design (cf. Creswell, 2012). Descriptive research is qualitative in nature (Creswell, 1994; 2012). This study was carried out in Machakos County, Kenya, where the native speakers of Machakos dialect of Kikamba language are found. Specifically, the research is aimed at collecting nouns from the speakers of the Machakos dialect of Kikamba in Mwala sub county Masii town (urban) and Muthetheni (rural). This study was qualitative in nature therefore a sample size of 50 respondents ( 25 males and 25 females) was considered valid. According to Creswell (2012) one can have 20-30 sample size in a qualitative study while Bertaux (1981) suggests fifteen as the smallest acceptable sample. Ritchie, \& Elam (2003) on the other hand suggest that qualitatively inclined samples should "lie under 50" (p. 84). The study used two data collection instruments namely, naturalistic observation and interviews. The study was guided by the following research objective:

i. Describe the syllable structure of Kikamba Nouns of Machakos dialect.

\section{RESEARCH METHODOLOGY}

ISSN: $2456-7620$ 


\section{RESULTS AND DISCUSSION: THE SYLLABLE STRUCTURE OF KIKAMBA NOUNS}

According to Ladefoged (1989) every language has its own combination of sounds within a syllable and word. All the syllable structures follow phonotactic rules which dictate combination of sounds that are allowed in a particular language. In the current paper, an analysis of Kikamba syllable structure of nouns is presented. The study sheds light on the internal syllable structure of Kikamba nouns which to the best of the researcher's knowledge, has not been fully handled by previous researchers. The paper has

\section{Kikamba Gloss}
a. /keləmo/
'lip'
b. /kana/
'child'
c. / koto/
'ear'
d. /mote/
'tree'

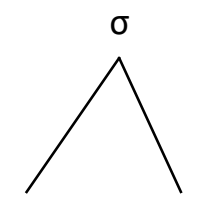

C

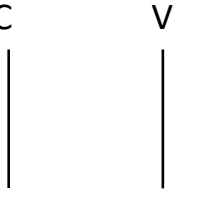

k

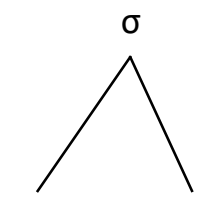

C

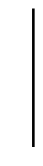

।

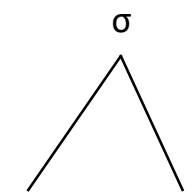

C

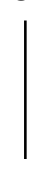

$\mathrm{m}$

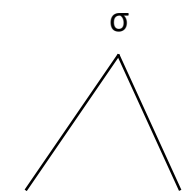

C

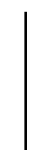

k observed four syllable structures found in Kikamba, that is, $\mathrm{CV}, \mathrm{V}, \mathrm{CV}$ : and CCV.

\subsection{Syllable}

A CV Syllable constitutes one consonant and one vowel segment. Clements \& Keyser (1983), states that CV Syllable is presumably found in all languages such as English, Arabic and Bantu languages. In this paper we observe that Kikamba has this syllable structure in greater part of its words as demonstrated below:

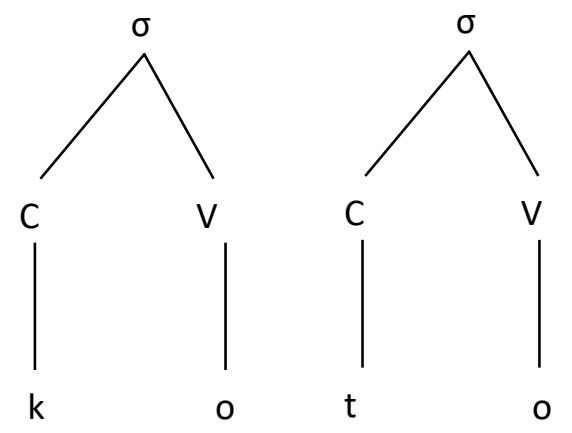

Kikamba nouns being a Bantu language depict A CV Syllable (C for consonant and V for a vowel). Most of the nouns constitutes one consonant and one vowel segment

ISSN: 2456-7620 


\subsection{CV: Syllable}

The data collected show that some open syllables nouns have the CV: Syllable. In this case, as much as the noun ends with a vowel the syllable comprises a consonant and a long vowel. This was a case where two vowels of the same kind follow each other yet treated as a monophthong. In this case the vowel cannot be split. Al-Ani (1970) and Akidah (2012) acknowledge the - VV sequence as one long vowel. Following Al-Ani (1970) and Akidah (2012) the current study groups the nouns with the CVV syllable as CV: That is consonant element that is followed by a single long vowel. The data below show some words with the CV: syllable:

\section{$\underline{\text { Kikamba Gloss }}$}
a) /mbu:/
a scream
b) /mu:/
a type of fruit
c) $/ \mathrm{ma}: \mathrm{o} /$
legs
d)/ndo:to/
a dream
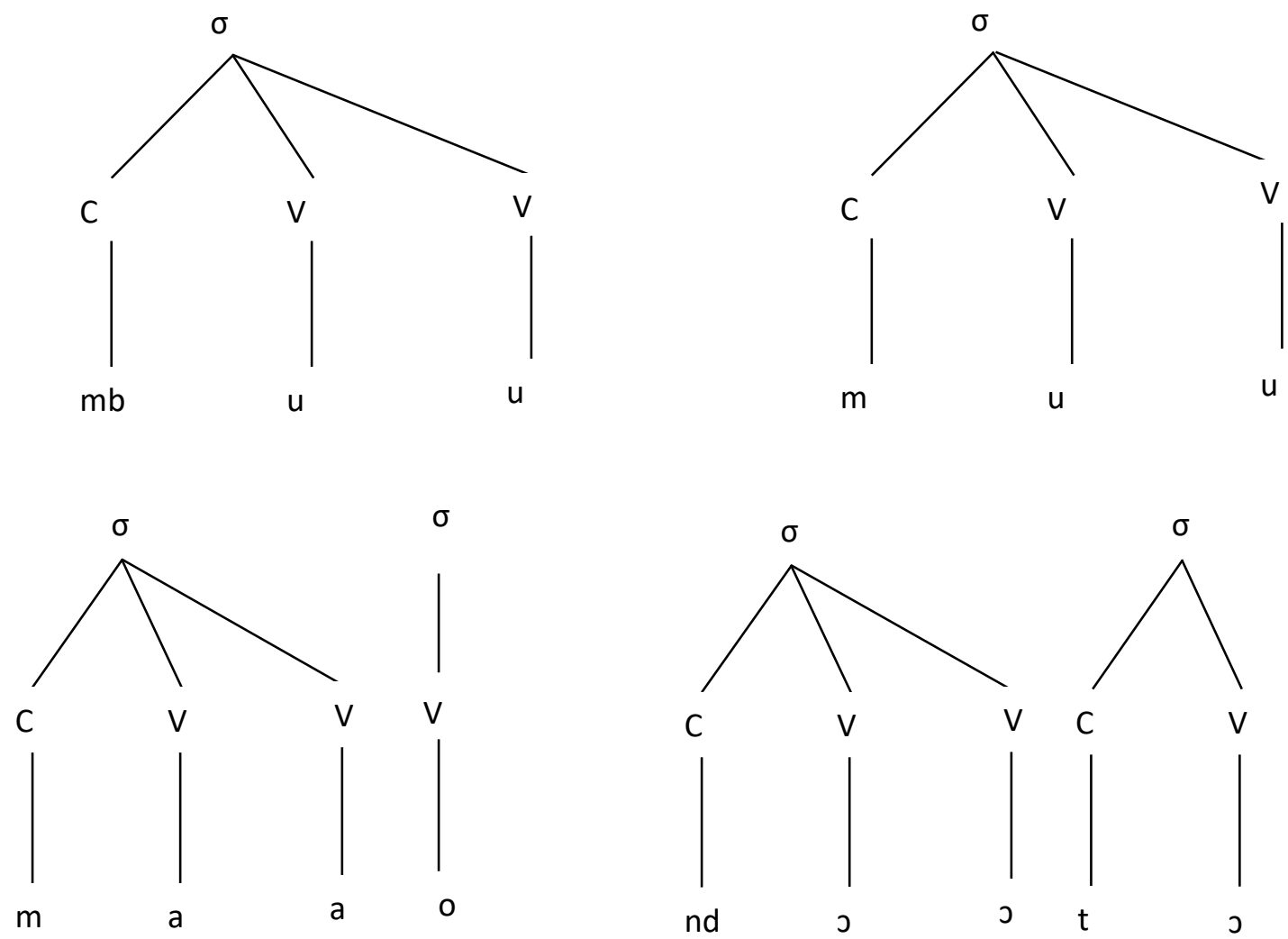

The above data show cases open syllable lengthening. This is a case where as much as words end with a short vowel they become long in open syllable. Kikamba nouns have the aspect of open syllable lengthening for instance the word $\boldsymbol{m b u}, \boldsymbol{m a o}$ and $\boldsymbol{m} \boldsymbol{u}$ from the glossary above.

\subsection{Syllable}

The data collected also reflected nouns with CCV Syllable structure. The CCV Syllable structure comprises a cluster of

two consonants ending with a vowel. That is, the Kikamba nouns have nouns with a syllable structure of a cluster of two consonants ending with a vowel. The researcher observes that this syllable type is usually found at a word or syllable initial position of Kikamba words. This Syllable type is found in words such as: 


\section{Kikamba Gloss}
a) /emwe/
one
b) /nzwee/
hair
c) $/ \mathrm{kjaa} /$
finger
d) $/ \mathrm{ka} \Phi \mathrm{jo} /$
knife
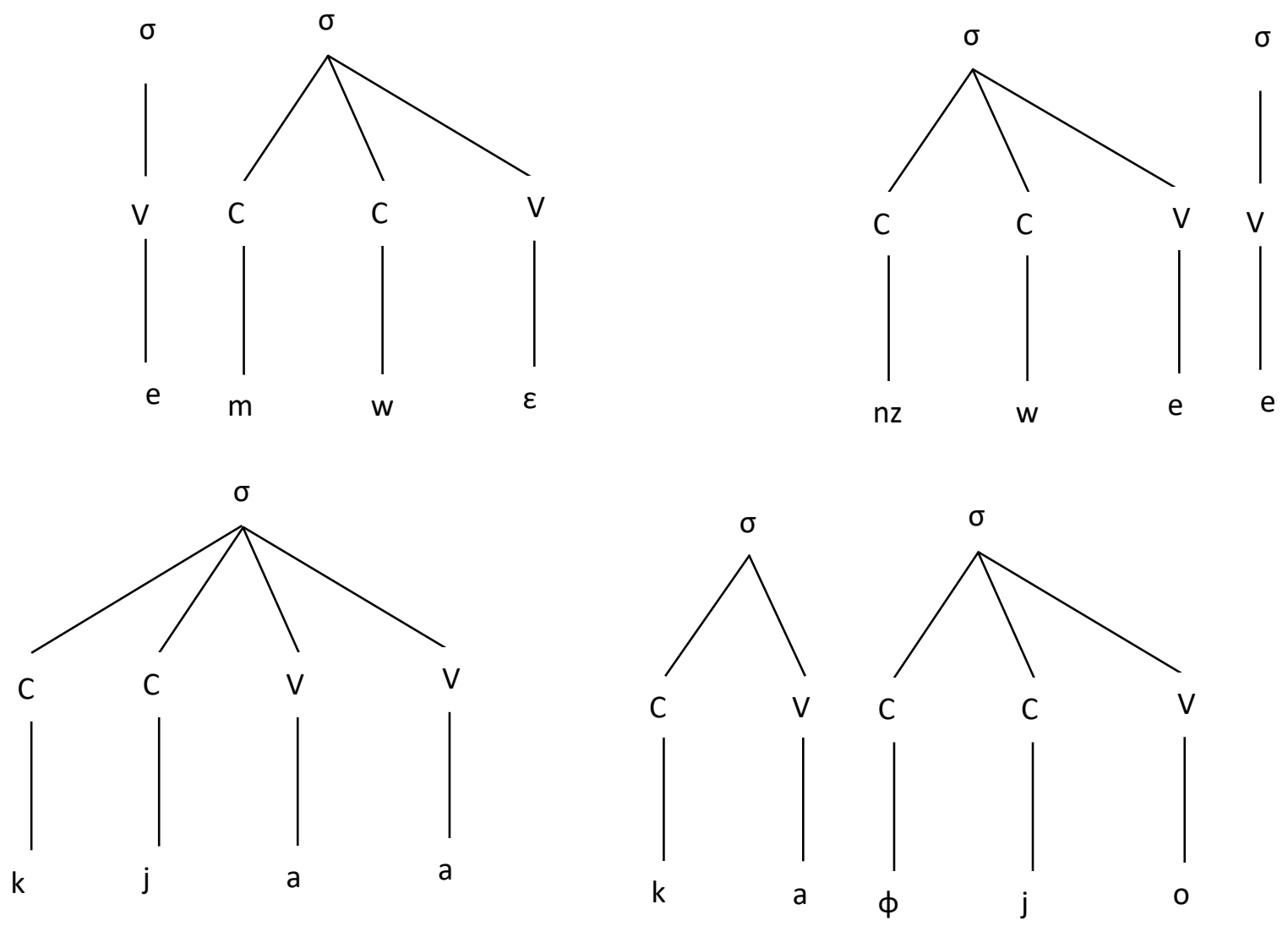

\subsection{Syllable}

A V (vowel) syllable constitutes only a vowel segment, a syllabic nasal or a syllabic liquid. This study has observed that it is only the V Syllable that constitutes only a vowel segment that is evident in Kikamba. The researcher observed For example

\section{Kiswahili Gloss}
a) /eio/
b) /eia/
c) /wea/
d) /sua/

\author{
a banana \\ milk/weed/lake \\ work \\ sun
}



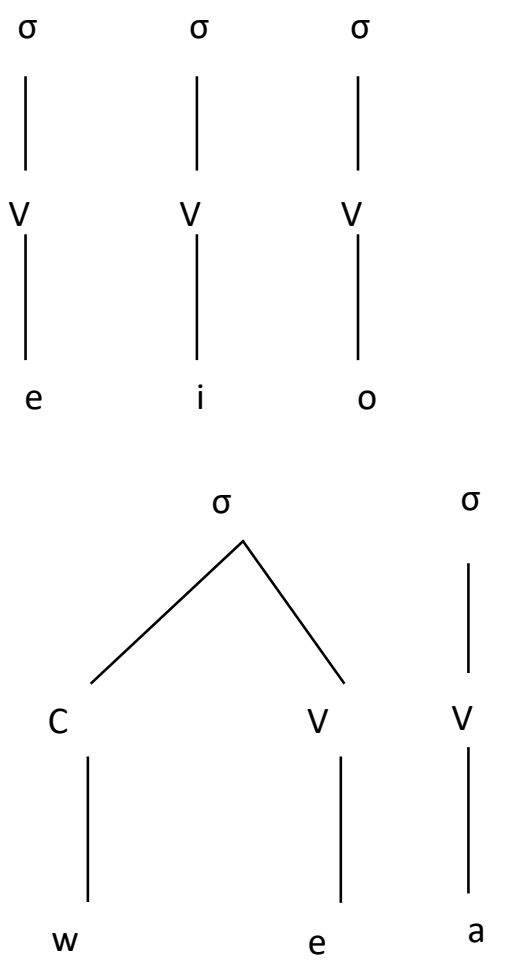

\section{CONCLUSION}

This paper sought to describe the syllable structure of Kikamba nouns. The researcher observed that Kikamba nouns have four syllable structures, which are; $\mathrm{CV}, \mathrm{CV}$ :, $\mathrm{CCV}, \mathrm{V}$. The first structure $\mathrm{CV}$ is in words that are made of a consonant and a vowel. For example the words /kelsmo/cvevev for ('lip'), /kana/ cvev for ('child'), /koto/ CVCV for ear and /mote/ /CVCV for tree. Kikambaa nouns also ended with a $\mathrm{V}$ but this time when the word is pronounced it ends with a long vowel. Examples of words with long $\mathrm{V}$ are and $\mathrm{CV}$ : structure are /mbu:/ CV: for a scream, /mu:/ CV: for a type of fruit, /ma:o/ CV: for legs and /ndo:to/ CV: for a dream. Kenya. The study concludes that syllable structure of Kikamba nouns is Open. The study findings revealed that the nouns either have CV, CV:, CCV or V. The study also revealed that Kikamba language is basicly open and not closed.

\section{REFERENCES}

[1] Akidah, M. A (2012) . A lexical phonology study of modern standard Arabic (MSA) Unpublished Phd. Thesis, University of Nairobi

[2] Al - Ani,S. (1970) Arabic phonology. The Hague : Mouton.

[3] Bertaux, Daniel (1981). From the life-history approach to the transformation of sociological practice. In Daniel Bertaux
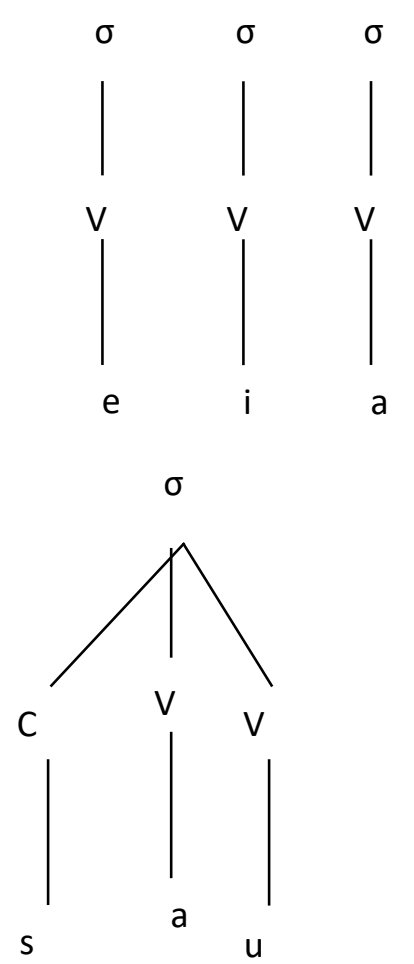

(Ed.), Biography and society: The life history approach in the social sciences (pp.29-45). London: Sage.

[4] Clements, G. \& S.J Keyser (1983). CV Phonology : A Generative Theory of the Syllable. Cambridge: The

[5] Creswell, J. (1994). Research design: Qualitative and quantitative approaches. London: Sage.

[6] Creswell, J. W. (2012). Qualitative inquiry and research design: Choosing among the five traditions. California: Thousand Oaks.

[7] Crystal, D. (1997). The Cambridge encyclopedia of language. 2nd (ed.) Cambridge: Cambridge University Press.

[8] Guthrie, M (1948). The classification of Bantu Languages. London : Oxford University Press.

[9] Heine, B (2000). African languages an introduction; Cambridge: Cambridge University Press.

[10] Hyman, L. M. (1975). Phonology: Theory \& Analysis. London: Holt -Rinnehert and Winston.

[11] Kahn, D, (1976). Syllable-Based Generalizations in English Phonology. MIT dissertation.

[12] Katamba, F. (1989). An Introduction to Phonology. London: Longman.

[13] Kioko, N. A. (2005). Theoretical Issues in the Grammar of Kikamba. Muenchen : Lincom.

[14] Kitavi, H. M(1992). A comparative study the Kitui North and Machakos dialects of Kikamba; UON: MA thesis.

[15] Ladefoged, P. (2000). A course in Phonetics. 4th Edition. Australia : Thomason Wordsworth .

[16] Lass, R. (1984). Phonology : An Introduction to BasicConcepts. Cambridge : Cambridge University Press.

ISSN: $2456-7620$ 
[17] Massamba, D. P. B. (1991). Phonological theory : History and development. Dar es Salaam University.

[18] Matthews, P.H. (1997). Oxford concise dictionary of linguistics. Reading: Cox and Wyman Ltd.Press.

[19] Mathooko, P.M. (2004). Towards integrative perspective of linguistic accommodation: A case study of Kikamba and Kitharaka. (Unpublished $\mathrm{PhD}$ thesis). Kenyatta University, Nairobi.

[20] Maundu, P. (1980). Reconstruction of Kikamba Consonantal Sounds; UON; MA Dissertation.

[21] Roach, P. (1994). English phonetics and Phonology. A practical Course. Cambridge, Cambridge University Press.

[22] Trask, R.L. (1996). A dictionary of phonetics and phonology. New York: Routledge.

[23] Trubetzkoy, N. S. (1969). Principles of Phonology. Berkeley : University of California Press.

[24] Urua, E. E. (2000). Ibibio phonetics and phonology. Cape Town: Centre for Advanced Studies of African Society.

[25] Yule, G. (1996). The study of language. Cambridge: Cambridge University Press.

[26] Whitley, W. H. \& M. G. Muli (1962). Practical Introduction to Kamba. London : Oxford University Press. 